\title{
NEW Preface
}

Welcome to the latest issue of the NEW Journal for Emerging Scholars in Australian Indigenous Studies. The journal features the best work submitted each year in the undergraduate elective subject Aboriginal Political History: Ideas, Action and Agency at the University of Technology Sydney.

This is an exciting time to be teaching and learning Aboriginal History. Aboriginal communities are engaging in their own history work, interrogating the colonial archive to recover and reclaim information about their cultural practices, telling counter-narratives to challenge eliminatory white histories, and producing new knowledge that speaks to their ongoing survival and resilience. Significant research projects such as the University of Newcastle's Massacre Map continue to challenge our understanding of the history of relationships between Indigenous and non-Indigenous Australians. The devastating impacts of climate change in the form of drought, water shortages and bush fires, have fostered a new interest in and appreciation of Indigenous land management practices developed over millennia. National history projects such as Encounters 2020, commemorating the 250th anniversary of Cook's arrival off the east coast of Australia, call on us to engage with the 'view from the shore' rather than simply the 'view from the ship' which has previously dominated so much of our understanding of Australia's colonial past. While many of these developments in the Australian history field should be celebrated, there is also a persistent lack of knowledge and understanding. Despite decades of curriculum reform, the most common reaction of non-Indigenous students on commencing this subject each year is "why didn't we know?" Researchers have lamented the piecemeal nature of current educational approaches as well as the levels of "disaffection, disinterest and denial of Aboriginal and Torres Strait Islander history" (Appleby \& Davis 2018).

In the Preface to the last issue we discussed the recent emphasis amongst historians on "deep time", with historians in Australia struggling to grapple with the immensity of Aboriginal history and culture spanning over 65,000 years. Beyond the challenges and opportunities offered by stretching our minds to try and encompass the idea of time immemorial, "truth-telling" about Australia's colonial history has also recently (re)emerged as a significant issue in Australia, with some arguing that this "moment of truth" will have major implications for the ongoing legitimacy of the Australian nation (McKenna 2018, Davis 2018). The Uluru Statement from the Heart (2017), the outcome of an unprecedented process of dialogue with Indigenous communities nationally, expressed the unanimous call from Indigenous community representatives for the establishment of "truth-telling" mechanisms to explore Aboriginal perspectives on Australia's colonial past (Commonwealth of Australia 2017). Standing alongside truth-telling was the call for an Indigenous "voice" to parliament, highlighting the failures of past efforts to engage with Indigenous communities on the basis of equal rights and equal partnership, a topic explored in a number of the contributions to this issue. 
Another theme that emerges from a number of the contributions to this issue is the importance of opening yourself up to the opportunity to learn about Aboriginal History, and we congratulate our contributors for seizing this opportunity so wholeheartedly. We would also like to acknowledge and sincerely thank our student editor, Nadine Silva, for her herculean efforts in copy-editing and compiling this bumper issue. Thanks to the UTS Gallery for granting permission to use the cover image, taken at Waraburra Nura, the Indigenous medicinal plant garden, a hidden treasure on Level 6 of the Tower Building. Visits to this and other sites allowed our students to take their learning about Aboriginal History out of the classroom and into the real world.

Anne Maree Payne and Jennifer Newman

Teaching staff, Aboriginal Political History: Ideas, Action and Agency 2019.

\section{References:}

Appleby, Gabrielle \& Davis, Meghan, 2018, "The Uluru Statement and the Promises of Truth", Australian Historical Studies, 49: 4, pp. 501-509.

Commonwealth of Australia 2017, Final Report of the Referendum Council, https://www.referendumcouncil.org.au/sites/default/files/report_attachments/Referendum_Council_ Final_Report.pdf

Davis, Megan, 2018, “Moment of Truth: Correspondence”, Quarterly Essay, No. 70, pp. 81-91.

McKenna, Mark, 2018, "Moment of Truth: History and Australia's Future”, Quarterly Essay, No. 69. 